\title{
Biographie und Persönlichkeit des Paulus
}

\author{
Hrsg. v. Eve-Marie Becker u. Peter Pilhofer
}

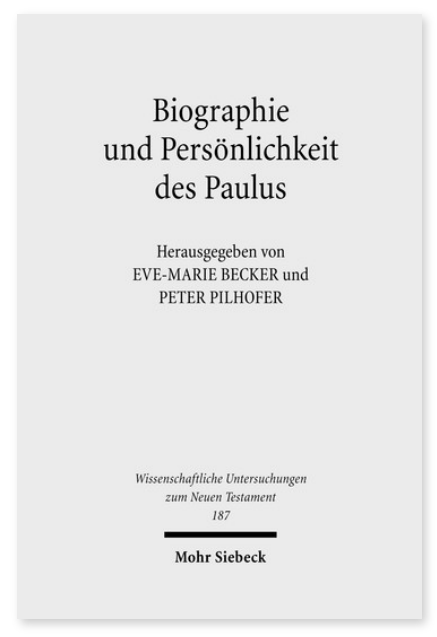

2005; unveränderte Studienausgabe; 2009. VIII, 392 Seiten. WUNT I 187

ISBN 978-3-16-151489-0 DOI 10.1628/978-3-16-151489-0 eBook PDF $59,00 €$

ISBN 978-3-16-149952-4

Broschur 59,00€
Der Band versammelt Beiträge aus unterschiedlichen Fachrichtungen zur Biographie und Person des 'Heiden-Apostels' Paulus.

Die Beiträge spiegeln den Stand und die Differenziertheit der gegenwärtigen Paulus-Forschung wider. Die Vielfalt der Ansätze liefert einen wichtigen Beitrag zum Problem der 'New Perspectives on Paul' und macht die Frage nach der 'Biographie und Person des Paulus' zu einem Paradigma der neutestamentlichen Wissenschaft.

»In jedem Falle wird die weitere Paulusforschung von diesem Buch und seinen vielfältigen Impulsen profitieren.« Tobias Nicklas in Bibel und Liturgie 79 (2006), S. 194-195

»Fresh perspectives are evident throughout this fascinating collection. ... A storehouse of learning.« International Review of Biblical Studies vol. 52 (2005/2006). p. 1662

»die Beiträge [bieten] gleichwohl gute Einblicke in die aktuelle internationale Paulusforschung und Anregungen für ihre die Disziplinen übergreifende Fortführung.«

Karl-Wilhelm Niebuhr in Theologische Literaturzeitung 132 (2007), S. 48

"The volume provides a good overview of aspects of Pauline studies discussed in German scholarship and elsewhere ... This publication is a valuable contribution to a specific issue in Pauline studies ..." Kathy Ehrensperger in Journal for the Study of the New Testament 29 (2007), p. 80-81

Eve-Marie Becker Geboren 1972; 2001 Dr. theol.; 2004 Habilitation; 2006-18 Professorin für neutestamentliche Exegese an der Universität Aarhus/Dänemark; 2016-17 Distinguished Visiting Professor of New Testament an der Emory University in Atlanta/USA; seit 2018 Professorin für Neues Testament an der Westfälischen Wilhelms-Universität Münster. https://orcid.org/0000-0002-0398-6448

Peter Pilhofer Geboren 1955; 1989 Promotion; 1994 Habilitation; Professor für Neues Testament an der Universität Erlangen.

Jetzt bestellen:

https://mohrsiebeck.com/buch/biographie-und-persoenlichkeit-des-paulus-9783161514890?no_cache=1 order@mohrsiebeck.com

Telefon: $+49(0) 7071-923-17$

Telefax: $+49(0) 7071-51104$ 